\title{
Simultaneous VHF radar backscatter and ionosonde observations of low-latitude $\mathbf{E}$ region
}

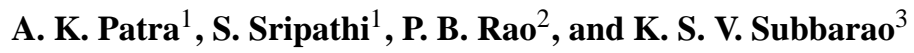 \\ ${ }^{1}$ National MST Radar Facility, Tirupati, India \\ ${ }^{2}$ National Remote Sensing Agency, Hyderabad, India \\ ${ }^{3}$ Space Physics Laboratory, VSSC, Trivandrum, India
}

Received: 15 February 2004 - Revised: 20 January 2005 - Accepted: 28 January 2005 - Published: 30 March 2005

\begin{abstract}
The first results of simultaneous observations made on the low-latitude field-aligned irregularities (FAI) using the MST radar located at Gadanki $\left(13.5^{\circ} \mathrm{N}, 79.2^{\circ} \mathrm{E}\right.$, $\operatorname{dip} 12.5^{\circ}$ ) and the $\mathrm{E}_{s}$ parameters using an ionosonde at a nearby station Sriharikota $\left(13.7^{\circ} \mathrm{N}, 80.1^{\circ} \mathrm{E}\right.$, dip $\left.12.6^{\circ}\right)$ are presented. The observations show that while the height of the most intense radar echoes is below the virtual height of $\mathrm{E}_{s}$ (h'E $E_{s}$ ) during daytime, it is found to be either below or above during nighttime. The strength of the FAI is better correlated with the top penetration frequency $\left(\mathrm{f}_{t} \mathrm{E}_{S}\right)$ and the blanketing frequency $\left(\mathrm{f}_{b} \mathrm{E}_{s}\right)$ during the night $(\mathrm{r}=0.4$ in both cases) as compared to the day ( $r=0.35$ and -0.04 , respectively). Furthermore, the signal strength of FAI is reasonably correlated with $\left(\mathrm{f}_{t} \mathrm{E}_{s}-\mathrm{f}_{b} \mathrm{E}_{s}\right)$ during daytime $(\mathrm{r}=0.59)$ while very poorly correlated during nighttime $(\mathrm{r}=0.18)$. While the radar observations in general appear to have characteristics close to that of mid-latitudes, the relationship of these with the $\mathrm{E}_{s}$ parameters are poorer than that of mid-latitudes. The observations reported here, nevertheless, are quite consistent with the expectations based on the gradient drift instability mechanism.
\end{abstract}

Keywords. Ionosphere (Equatorial ionosphere, Ionospheric irregularities, Plasma waves and instabilities)

\section{Introduction}

The $\mathrm{E}$ region field-aligned irregularities (FAI) in the equatorial- and auroral-electrojet have been studied extensively (for details, see Kelley, 1989). Significant progress has also taken place in understanding the mid-latitude $\mathrm{E}$ region FAI, mainly in the last decade (Fukao et al., 1998 and the references therein). The observations on low-latitude FAI, on the other hand, have just begun. The observations on the low-latitude FAI that are available in the literature are those made by the Gadanki MST radar $\left(13.5^{\circ} \mathrm{N}, 79.2^{\circ} \mathrm{E}\right.$, dip $12.5^{\circ}$ ), located in southern part of India (Krishna

Correspondence to: A. K. Patra

(patra_nmrf@rediffmail.com)
Murthy et al., 1998; Choudhary and Mahajan, 1999; Patra and Rao, 1999; Patra et al., 2002a,b; 2004; Pan and Rao, 2002; Sripathi et al., 2003) and by the Piura VHF radar $\left(5.2^{\circ}, 80.6^{\circ} \mathrm{W} ; 13.9^{\circ}\right.$ dip angle), located in northern Peru (Woodman et al., 1999; Chau and Woodman, 1999; Chau et al., 2002). These radars are located just outside the equatorial electrojet (EEJ) region and have revealed many interesting and new features of the low-latitude $\mathrm{E}$ region FAI, including the general characteristics that are so different from those at either the equator or mid-latitudes (Chau et al., 2002; Patra et al., 2004). For example, the occurrence characteristics of the echoes differ remarkably from that of the equatorial electrojet in a sense that during noontime, when the electrojet echoes are observed to be stronger, the occurrence probability of the low-latitude echoes is minimum (although the echoes occur both during the day and night). The fact that the echoes are detected during the day is in contrast to the mid-latitude observations, which is basically a nighttime phenomenon. Further, the low-latitude FAI show the kilometer scale wave-like structures quite similar to the EEJ large-scale gradient drift waves (Patra et al., 1999; 2002a) and quasi-periodic (QP) echoes quite similar to that of mid-latitudes (Choudhary and Mahajan, 1999).

While the EEJ FAI are related to the EEJ strength, the midlatitude FAI are believed to be closely related to the level of sporadic $\mathrm{E}\left(\mathrm{E}_{s}\right)$ activity. Several studies, including that during the SEEK campaign, have been made at mid-latitudes to understand the source of these echoes through their relationship with $\mathrm{E}_{S}$ (e.g. Yamamoto et al., 1992; Hussey et al., 1998; Ogawa et al., 1998; 2002). The correlation of FAI and $\mathrm{E}_{s}$, in general, is found to be good and the generation mechanism of the FAI is believed to be gradient drift instability (GDI). There have been cases that the FAI do not relate to the $\mathrm{E}_{s}$ layer (for example, the $90-100 \mathrm{~km}$ echoes observed during the post-sunrise period) (Ogawa et al., 1998). Similar efforts have been made for equatorial anomaly region over Chung-Li, to study the relationship of the FAI and the $\mathrm{E}_{s}$ (Pan et al., 1998; Lee et al., 2000). The conclusions are quite similar to that of the mid-latitudes. 

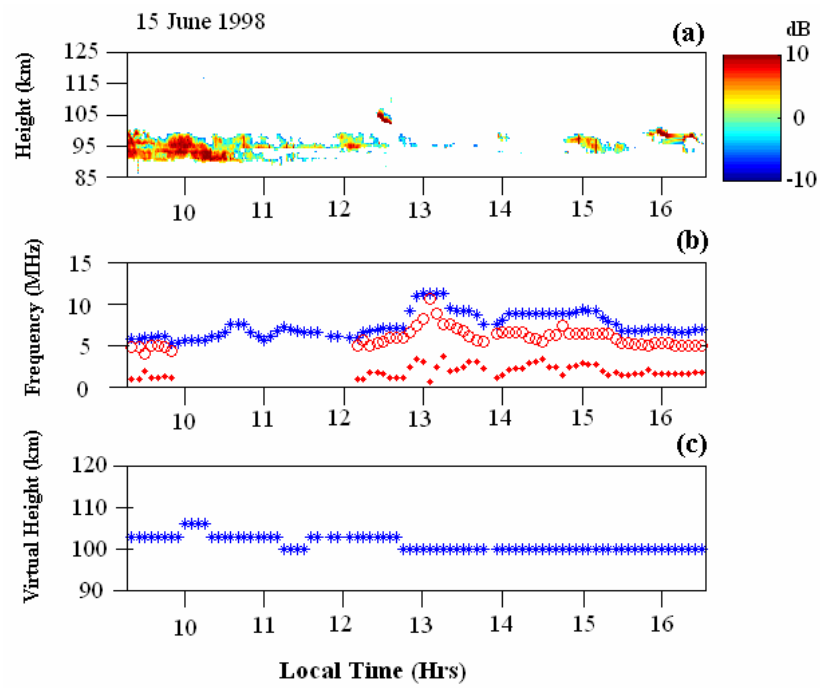

(c)

Fig. 1. (a) Height-time-intensity (SNR) map of the FAI, (b) time variations of the three parameters $\mathrm{f}_{t} \mathrm{E}_{s}$ (star), $\mathrm{f}_{b} \mathrm{E}_{s}$ (open circle), $\mathrm{f}_{t} \mathrm{E}_{s}-\mathrm{f}_{b}$ Es (diamond), and (c) time variation of height of the $\mathrm{E}_{s}$ layer observed during daytime on 15 June 1998.
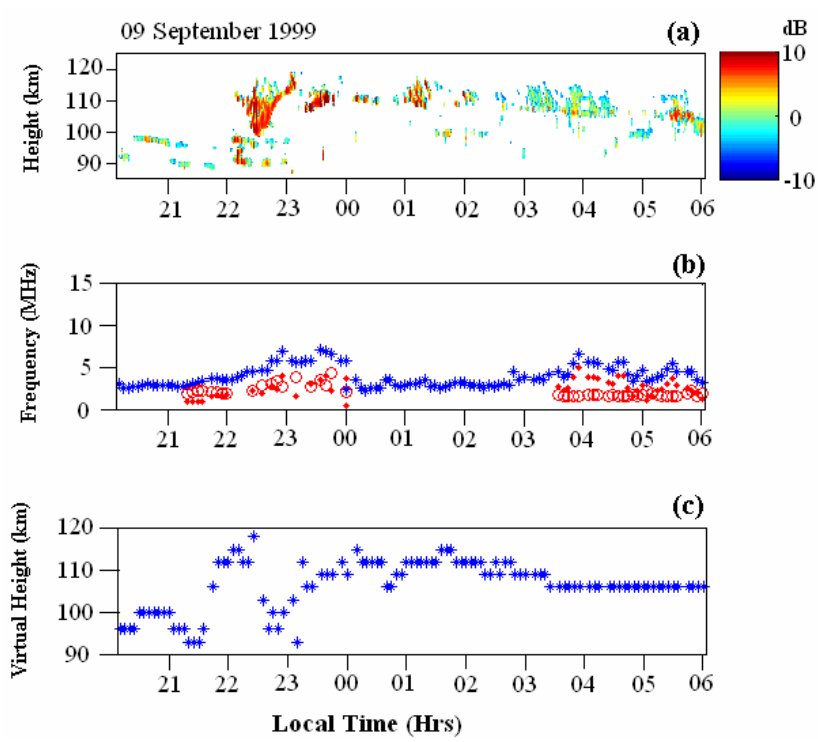

Fig. 2. Same as Fig. 1, but for nighttime on 9 August 1999.

For the low-latitudes outside the EEJ, the electric fields are small as compared to the EEJ, and sporadic E activities are also relatively less as compared to mid-latitudes. The irregularities, on the other hand, are found to occur both during the day and night. During the day, the occurrence of the irregularities, although less as compared to the EEJ, is remarkably more as compared to mid-latitudes. Since the electric field is low at low-latitudes, Krishna Murthy et al. (1998) conjectured that a blanketing of type $\mathrm{E}_{S}$, providing a sharp electron density gradient, would be required for the excitation of GDI during daytime conditions. Raghavarao et al. (2002), on the other hand, proposed that the variability of the EEJ system is likely to be responsible for the day-to-day variation in the occurrence of the off-EEJ FAI during daytime.

In the above context, a study on the relationship of the FAI with the $\mathrm{E}_{s}$ over low-latitude would be of significant value. In this paper, we present the first results on the simultaneously observed FAI using the MST radar located at Gadanki and the $\mathrm{E}_{s}$ parameters using an ionosonde located at Sriharikota $\left(13.7^{\circ} \mathrm{N}, 80.1^{\circ} \mathrm{E}\right.$, dip $\left.12.6^{\circ}\right)$, a rocket launching station. These results are discussed in light of similar studies made at other latitudes.

\section{Observations}

The observations on the low-latitude E region FAI and the $\mathrm{E}_{s}$ parameters reported in this paper were made simultaneously on a few occasions during 1998-1999 using the MST radar located at Gadanki and an ionosonde (KEL-IPS42) located at Sriharikota. The Gadanki MST radar is a monostatic coherent-pulsed Doppler radar operating at $53 \mathrm{MHz}$ with a peak power aperture product of $3 \times 10^{10} \mathrm{~W} \mathrm{~m}^{2}$ (Rao et al., 1995). For the $\mathrm{E}$ region studies, the antenna beam was positioned at $13^{\circ}$ off zenith due north, which is perpendicular to the magnetic field, for the reception of the coherent backscattered echoes. The height resolutions of the observations corresponding to the MST radar and the ionosonde are $600 \mathrm{~m}$ and $3 \mathrm{~km}$, respectively. It may be mentioned that the local time at Sriharikota is only 4 min ahead of Gadanki.

Figures 1a-c show the signal strength of the FAI and the $\mathrm{E}_{s}$ parameters (virtual height of $\mathrm{E}_{s}, \mathrm{~h}^{\prime} \mathrm{E}_{s}$; top penetration frequency of $\mathrm{E}_{s}, \mathrm{f}_{t} E_{s}$; blanketing frequency, $\mathrm{f}_{b} \mathrm{E}_{s}$; and $\mathrm{f}_{t} \mathrm{E}_{s}-\mathrm{f}_{b} \mathrm{E}_{s}$ ) observed during daytime on 15 June 1998. The frequencies $\mathrm{f}_{t} \mathrm{E}_{s}$ and $\mathrm{f}_{b} \mathrm{E}_{s}$ have been deduced following the scaling procedure adopted by Reddy and Rao (1968). Figure $1 \mathrm{a}$ is the height time intensity map representing the height time variations of the signal-to-noise ratio of the backscattered signals. Signals are found to be quite strong until 11:00 IST (Indian Standard Time that corresponds to $81.5^{\circ} \mathrm{E}$ longitude) and afterwards become weak and discrete as a function of time. After about 13:00 IST, for about $2 \mathrm{~h}$, the signals become extremely weak. This feature is quite common between 11:00-14:00 IST over Gadanki (Krishna Murthy et al., 1998; Patra et al., 2004). The echoes are confined to altitudes below $100 \mathrm{~km}$ except for a very brief period at $\sim 12: 30$ IST, when a patch of FAI is seen at an altitude just below $105 \mathrm{~km}$. Figure $1 \mathrm{~b}$ presents $\mathrm{f}_{t} \mathrm{E}_{s}\left(\right.$ star), $\mathrm{f}_{b} \mathrm{E}_{s}$ (open circle), and $\mathrm{f}_{t} \mathrm{E}_{s}-\mathrm{f}_{b} \mathrm{E}_{s}$ (diamond) as a function of time. Similarly, Figure 1c presents $\mathrm{h}^{\prime} \mathrm{E}_{s}$. The maximum $\mathrm{f}_{t} \mathrm{E}_{s}$ is found to be $11.3 \mathrm{MHz}$ occurring around 13:00 IST. Blanketing $\mathrm{E}_{s}$ has been observed except for the period 10:00-12:00 IST. The maximum $\mathrm{f}_{b} \mathrm{E}_{s}$ is found to be $10.6 \mathrm{MHz}$ occurring just after 13:00 IST. The maximum value of $\mathrm{f}_{t} \mathrm{E}_{s}-\mathrm{f}_{b} \mathrm{E}_{s}$ is found to be $3.7 \mathrm{MHz}$. There do not seem to be any clear relationship of the strength of the FAI with either $\mathrm{f}_{t} \mathrm{E}_{s}$ or $\mathrm{f}_{b} \mathrm{E}_{s}$ or $\mathrm{f}_{t} \mathrm{E}_{s}-\mathrm{f}_{b} \mathrm{E}_{s}$. The height of FAI, in general, is found to be 
below $\mathrm{h}^{\prime} \mathrm{E}_{s}$ accept for a brief period at around 12:30 IST, when a patch of FAI is seen just above $\mathrm{h}^{\prime} \mathrm{E}_{s}$.

Figures $2 \mathrm{a}-\mathrm{c}$ show the signal strength of the FAI and the $\mathrm{E}_{s}$ parameters observed during nighttime on 9 August 1999 in a similar way as shown in Fig. 1. The intensity map (Fig. 2a) in the beginning of the run shows thin descending FAI layers until 23:00 IST. The layers seem to descend to an altitude below $90 \mathrm{~km}$. The high altitude echoes are found to appear soon after 22:00 IST and the signals are found to be the strongest. Then the echoing region remains almost at the same height until 06:00 IST in the morning. Thin weak layers are also observed at $\sim 01: 30$ IST and $\sim 05: 00$ IST for brief periods. The high altitude echoes show structures that are quasi-periodic (QP) in nature. Signals associated with the high-altitude echoing region before 02:00 IST, however, are found to be stronger than the rest of the run. Figure $2 b$ shows that $\mathrm{E}_{S}$ is present throughout the run. During 21:2000:00 IST and 03:30-06:00 IST, it also shows the presence of a blanketing $\mathrm{E}_{s}$. The maximum values of $\mathrm{f}_{t} \mathrm{E}_{s}$ and $\mathrm{f}_{b} \mathrm{E}_{s}$ are found to be $7 \mathrm{MHz}$ and $4.3 \mathrm{MHz}$, respectively. The difference of these frequencies, wherever present, is found to maximize at $4.1 \mathrm{MHz}$. Again, like the daytime, there does not seem to be any clear correlation between the signal intensity with either $\mathrm{f}_{t} \mathrm{E}_{s}$ or $\mathrm{f}_{b} \mathrm{E}_{s}$ or $\mathrm{f}_{t} \mathrm{E}_{s}-\mathrm{f}_{b} \mathrm{E}_{s}$, except during 22:30-24 IST. Figure 2c shows a reasonably good correlation between $\mathrm{h}^{\prime} \mathrm{E}_{S}$ and the height of FAI. When the FAI are found to occur at higher altitudes after 22:00 IST, $\mathrm{h}^{\prime} \mathrm{E}_{S}$ layer is also found to go up. The layer is seen to come down temporarily at $\sim 22: 40$ IST and then it goes to higher altitudes. In general, the heights of FAI and that of $\mathrm{h}^{\prime} \mathrm{E}_{S}$ are found to agree very well.

Figures $3 \mathrm{a}$ and $\mathrm{b}$ show the virtual heights of the $\mathrm{E}_{s}$ layer, $\mathrm{h}^{\prime} \mathrm{E}_{S}$ (open circle) and that of the strongest signal related to the FAI (star) as a function of time observed on 12 days and 15 nights, respectively. Note that during 06:00-07:00 IST and 16:30-17:30 IST, there are no FAI data since the radar experiments were not conducted during that time. The figures clearly show that during daytime, the heights at which the FAI occur are lower than $\mathrm{h}^{\prime} \mathrm{E}_{s}$ and this difference is mostly $5-10 \mathrm{~km}$. During nighttime, however, the heights of the FAI and $\mathrm{h}^{\prime} \mathrm{E}_{s}$ are both scattered unlike daytime.

Figures $4 \mathrm{a}$ and $\mathrm{b}$ show the relationship between the height of the FAI and $\mathrm{h}^{\prime} \mathrm{E}_{S}$ in the form of a scatter plot corresponding to daytime and nighttime, respectively. The straight line in each panel is the least-square fit to the scatter plot. The slope and intercept of the straight line (in the form of $\mathrm{Y}=\mathrm{a}+\mathrm{bX}$ ), as well as the value of the linear correlation coefficient (r), are indicated in each panel. The correlation coefficients are 0.39 and 0.14 for daytime and nighttime, respectively. The estimated standard deviation is shown to be 3.31 and 12.22 for daytime and nighttime, respectively. During the day, except for a few cases, the values of $\mathrm{h}^{\prime} \mathrm{E}_{s}$, in general, are higher (5$10 \mathrm{~km}$ ) than the height of FAI. But during the night, no such clear trend can be discerned.

The occurrence of a blanketing $\mathrm{E}_{S}$ is quite common at this latitude. Figure 5 shows the percentage occurrence of blanketing $\mathrm{E}_{S}$ as a function of time. The percentage occurrence
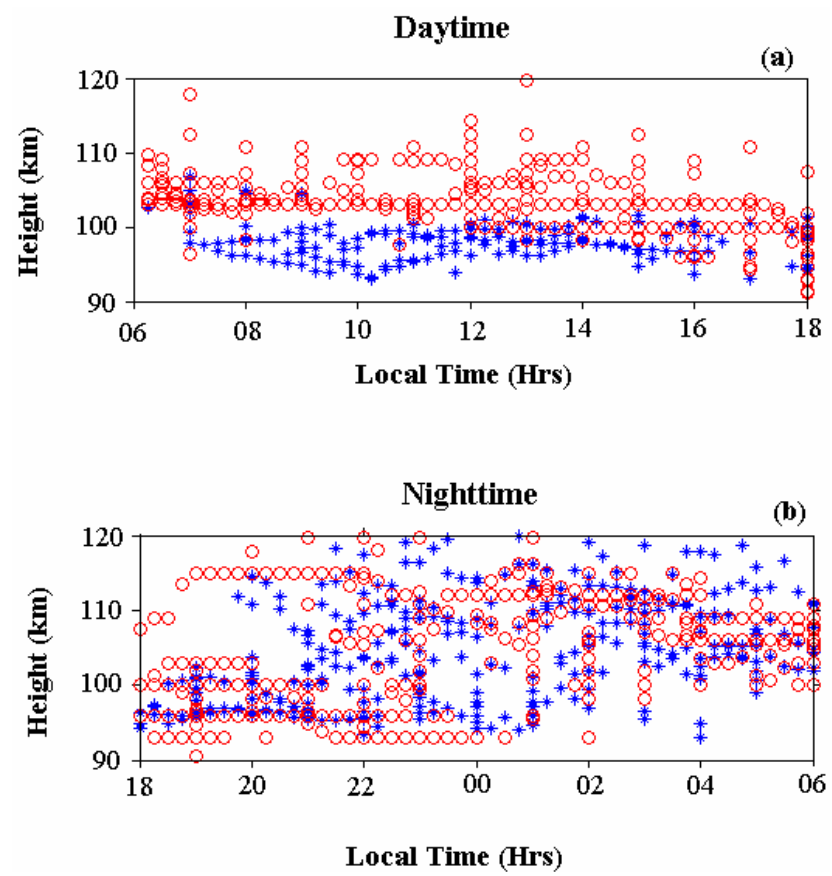

Fig. 3. A comprehensive picture depicting the virtual height of the $\mathrm{E}_{S}$ layers, $\mathrm{h}^{\prime} \mathrm{E}_{S}$ (open circle) and height of the most intense FAI (star) observed during (a) daytime on 12 days and (b) nighttime on 15 nights. (a) Daytime

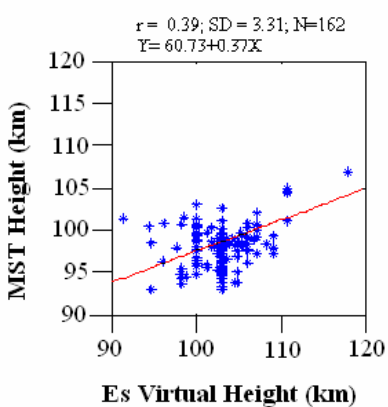

(b) Nighttime

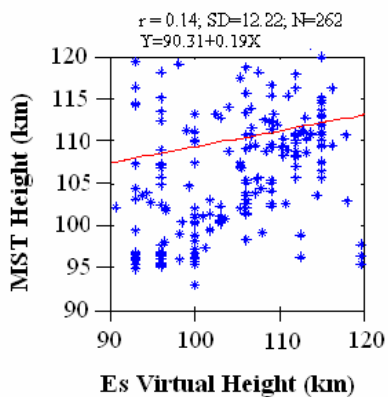

Fig. 4. Scatter plots of the virtual height of $E_{S}\left(h^{\prime} E_{S}\right)$ and that of the most intense FAI for (a) daytime and (b) nighttime. The correlation coefficients and least-square fit lines are also shown.

of blanketing $\mathrm{E}_{S}$ lies in the range of $8 \%-89 \%$, which maximizes at $\sim$ 07:00 IST and 16:30 IST, with a minimum being immediately after local midnight. During noon hours, the percentage occurrence is $\sim 50 \%$.

Figures $6 \mathrm{a}$ and $\mathrm{b}$ show the relationships of $\mathrm{f}_{t} \mathrm{E}_{s}, \mathrm{f}_{b} \mathrm{E}_{s}$ and $\mathrm{f}_{t} \mathrm{E}_{s}-\mathrm{f}_{b} \mathrm{E}_{s}$ with the strength of the FAI (SNR) in the form of a scatter plot for the day and nigh, respectively. It may be noted that corresponding to the occurrence of FAI, the values of $\mathrm{f}_{t} \mathrm{E}_{s}, \mathrm{f}_{b} \mathrm{E}_{s}$ and $\mathrm{f}_{t} \mathrm{E}_{s}-\mathrm{f}_{b} \mathrm{E}_{s}$ are in the range of $3.1-11.2 \mathrm{MHz}$, 2.4-8.3 MHz and $0.5-5.2 \mathrm{MHz}$ for daytime and $1.8-9 \mathrm{MHz}$, 1.6-5.3 MHz and 0.2-5.2 MHz for nighttime. The most commonly occurring values of $\mathrm{f}_{t} \mathrm{E}_{s}$ and $\mathrm{f}_{b} \mathrm{E}_{s}$ are about $7 \mathrm{MHz}$ 


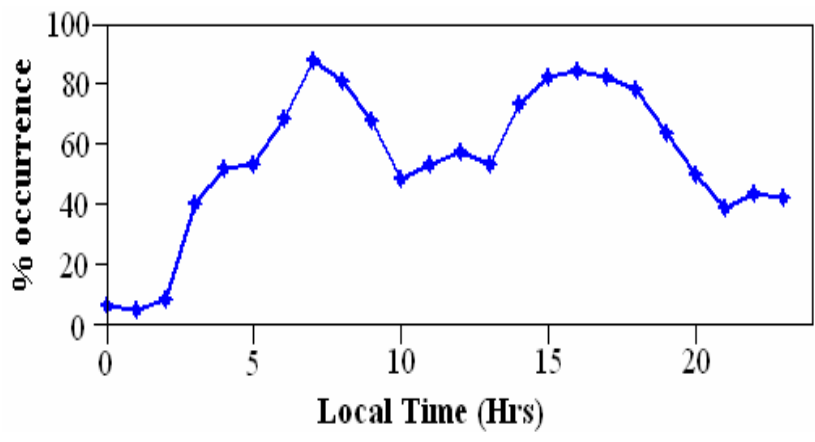

Fig. 5. Percentage occurrence of blanketing $E_{S}$ as a function of time.
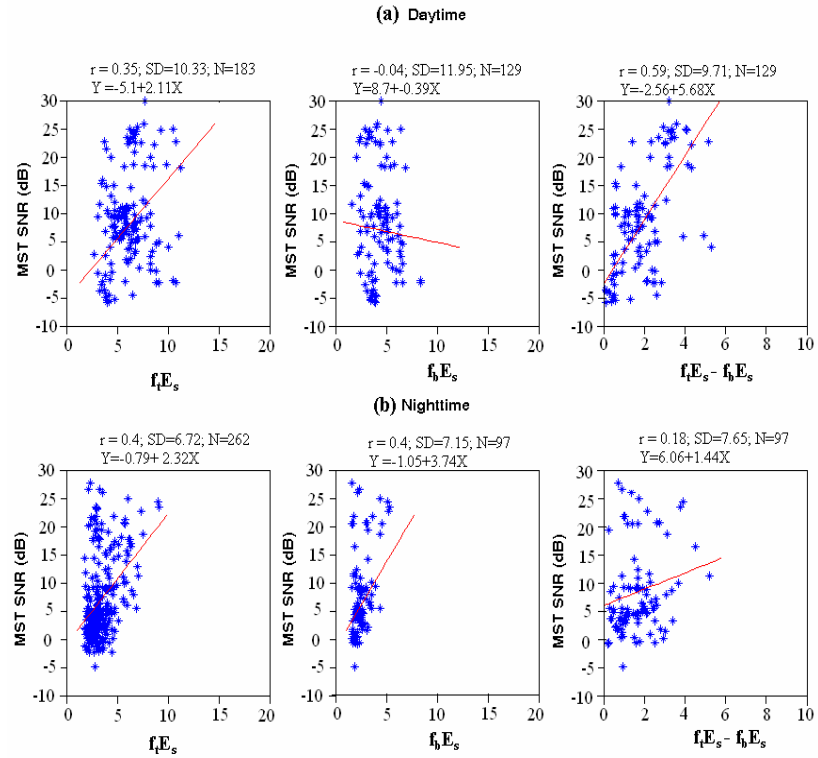

Fig. 6. Scatter plots of three $\mathrm{E}_{S}$ parameters $\left(\mathrm{f}_{t} \mathrm{E}_{S}, \mathrm{f}_{b} \mathrm{E}_{S}\right.$ and $\mathrm{f}_{t} \mathrm{E}_{S}-$ $\mathrm{f}_{b} \mathrm{E}_{S}$ ) with FAI strength (SNR) for (a) daytime and (b) nighttime. The correlation coefficients and least-square fit lines are also shown.

and $5 \mathrm{MHz}$ for daytime and $5 \mathrm{MHz}$ and $3 \mathrm{MHz}$ for nighttime. During daytime, SNR seems to increase, in general, with $\mathrm{f}_{t} \mathrm{E}_{s}$ and $\mathrm{f}_{t} \mathrm{E}_{s}-\mathrm{f}_{b} \mathrm{E}_{s}$ and show almost no correlation with $\mathrm{f}_{b} \mathrm{E}_{s}$. During nighttime, SNR seems to increase with $\mathrm{f}_{t} \mathrm{E}_{s}, \mathrm{f}_{b} \mathrm{E}_{s}$ and poorly with $\mathrm{f}_{t} \mathrm{E}_{s}-\mathrm{f}_{b} \mathrm{E}_{s}$. In these figures, the least-square fit line and correlation coefficients are also mentioned in each panel. The correlation coefficient of FAI strength with $\mathrm{f}_{t} \mathrm{E}_{s}$, $\mathrm{f}_{b} \mathrm{E}_{s}$ and $\mathrm{f}_{t} \mathrm{E}_{s}-\mathrm{f}_{b} \mathrm{E}_{s}$, respectively, are $0.35,-0.04,0.59$ for daytime and $0.4,0.4,0.18$ for nighttime. The estimated standard deviations are 10.33, 11.95, 9.71 for daytime and 6.72, $7.15,7.65$ for nighttime. The corresponding uncertainties in the coefficients a and b, denoted by $\sigma_{a}$ and $\sigma_{b}$, are: $\sigma_{a}=2.54$, 3.66, 1.47 for daytime and $\sigma_{a}=1.19,2.39,1.54$ for nighttime; $\sigma_{b}=0.41,0.83,0.69$ for daytime and $\sigma_{b}=0.32,0.89,0.79$ for nighttime.

\section{Discussion}

The above observations show that the FAI occur both during daytime and nighttime, with weak signals during noon hours. During the day, the heights of the intense FAI are $5-10 \mathrm{~km}$ below $\mathrm{h}^{\prime} \mathrm{E}_{s}$ except on a few occasions when the heights of FAI are more than $\mathrm{h}^{\prime} \mathrm{E}_{S}$. During the night, however, there is no such tendency. FAI occur both below and above $\mathrm{h}^{\prime} \mathrm{E}_{s}$ and the observations show a highly scattered picture. It may be mentioned that $\mathrm{h}^{\prime} \mathrm{E}_{s}$ is the virtual height of $\mathrm{E}_{s}$ and the true height of $\mathrm{E}_{s}$ would be a few kilometers less than $\mathrm{h}^{\prime} \mathrm{E}_{s}$.

For the mid-latitude station of Shigaraki $\left(34.8^{\circ} \mathrm{N}\right.$, $\left.136.1^{\circ} \mathrm{E}\right)$, Japan, Ogawa et al. (1998) compared the heights of the field-aligned echoes and the $\mathrm{E}_{s}$ observed during nighttime and they did not find any correspondence between them. Moreover, they found that the heights of the radar echoes in the morning (3-7 LT) echoes are at 10-20 km below the $\mathrm{E}_{s}$ virtual height. Nighttime observations of FAI and $\mathrm{E}_{s}$ have also been reported from Chung-Li $\left(24.9^{\circ} \mathrm{N}, 121^{\circ} \mathrm{E}\right)$, Taiwan (Pan et al., 1998; Lee et al., 2000). While Pan et al. (1998) did not find a correlation between the heights of $\mathrm{E}_{s}$ and that of the FAI, Lee et al. (2000) showed good correlation between these two. They have shown that, the lowest height at which FAI occur correlate fairly well with the virtual height of the $\mathrm{E}_{s}$ layer. They have shown that due to the underlying ionization and electron density, the virtual height is greater than that of the bottom of the irregularity structures by about $5-10 \mathrm{~km}$. They suggested that the absence of correlation is due to a beam broadening effect in the ionosonde observations.

Over Gadanki, during daytime, $\mathrm{h}^{\prime} \mathrm{E}_{s}$ is higher than that of the most intense FAI. During daytime, when the polarization electric field is upward, the positive gradient of electron density existing at the bottomside of the peak $\mathrm{E}_{S}$ is expected to be unstable through gradient drift instability. Accordingly, the FAI are expected to occur at heights where gradient is maximum and that is expected to be below the peak of the $\mathrm{E}_{s}$ layer. At the peak of the $\mathrm{E}_{s}$ layer, the gradient is expected to be the minimum. Accordingly, the height of the most intense FAI is expected to be lower than the peak height of $\mathrm{E}_{s}$ (which is somewhat lower than $\mathrm{h}^{\prime} \mathrm{E}_{s}$ ). The difference between these two heights (height of FAI and $\mathrm{h}^{\prime} \mathrm{E}_{s}$ ) is found to be $5-10 \mathrm{~km}$. For the daytime model electron density profile, the difference between the virtual height and the true height of $\mathrm{E}_{s}$ would be about $5 \mathrm{~km}$. Since the height of FAI in our presentation corresponds to the strongest signal observed, the difference between the height of FAI and $\mathrm{h}^{\prime} \mathrm{E}_{s}$ would be somewhat larger since the strongest FAI is expected to occur at the sharpest electron density gradient, not at the height of the peak electron density. Since $\mathrm{h}^{\prime} \mathrm{E}_{s}$ is the virtual height and the true height of $\mathrm{E}_{s}$ is less than that, the difference can be easily accounted for. Further, the precise height information cannot be known from the ionogram. Due to the corrugations in the $\mathrm{E}_{s}$ layer and the broad beam of the ionosonde antenna, echoes coming from the same height could appear at a higher range in the ionogram. Distinguishing the range and height, however, is difficult in the ionogram. On a few occasions, 
when the heights of the FAI are seen to be more than that of $\mathrm{h}^{\prime} \mathrm{E}_{s}$, the FAI could be related to a patchy type of $\mathrm{E}_{s}$ instead of the $\mathrm{E}_{s}$ layer. FAI observed around 12:30 IST at $\sim 105 \mathrm{~km}$ on 15 June 1998 seem to indicate this fact. It is quite possible that an intense $\mathrm{E}_{S}$ patch could be locally unstable through a polarization process, since a polarization process can take place due to the finite dimension of the $\mathrm{E}_{s}$ patch.

During nighttime, however, there is no such relation. If we assume the $\mathrm{E}_{s}$ layer to be a single Gaussian layer, then in the presence of a downward electric field, it is expected that the height region above the height of the peak $\mathrm{E}_{s}$ layer would be unstable. Accordingly, the height of occurrence of the FAI is expected to be above the height of the peak electron density. During nighttime, however, the assumption of a single Gaussian-type layer could fail quite often. The nighttime E region electron density profile often shows jaggedness (Prakash et al., 1972). Hence, the FAI could be expected at several height regions where the instability criteria are satisfied. Therefore, it is not necessary that the height of intense FAI and $\mathrm{E}_{s}$ should match. Lee et al. (2000) found that the height of the $\mathrm{E}_{s}$ and the FAI differ by $5-10 \mathrm{~km}$ and concluded that the absence of correlation is due to a beam broadening effect of the ionosonde. We think that even if we have a narrow beam for the ionosonde as small as that of the radar, the height of the $\mathrm{E}_{S}$ and the bottommost height of the FAI need not agree with each other, since the FAI could occur at several heights due to the jaggedness of the nighttime electron density profile. However, when a single peak electron density layer exists, good agreement between the two heights could be expected. From this viewpoint, the observations on the height comparison of FAI and $\mathrm{h}^{\prime} \mathrm{E}_{s}$ presented here seems to be quite similar to that observed over mid-latitudes.

The occurrence probability of a blanketing $\mathrm{E}_{S}$ show clear peaks at about 07:00 IST and 16:30 IST, with the minimum being during post-midnight hours. It may be mentioned that the radar echoes are quite strong during the post-midnight hours and also show remarkable height structures. On the other hand, during noon hours, when the occurrence probability of a blanketing $\mathrm{E}_{s}$ is about $50 \%$, normally the echoes are weak and also the probability of occurrence is the lowest. Patra et al. (2004) have shown that the peak percentage of FAI occurrences during daytime and nighttime are $95 \%$ and $75 \%$, respectively. The most probable times for FAI are just after sunrise, with a peak percentage occurrence of $95 \%$, just before sunset, with a peak percentage occurrence of $80 \%$ and least likely around noon, with values $<30 \%$. Accordingly, the percentage occurrence of FAI and percentage occurrence of blanketing $\mathrm{E}_{s}$ as a function of local time seem to agree reasonably well with each other, except during postmidnight for about $2 \mathrm{~h}$. The FAI strength (SNR), however, does not agree well with the activity of blanketing $E_{s}\left(f_{b} E_{s}\right)$, as has been seen in Fig. 6. This seems to suggest that the blanketing activity is important for the occurrence of FAI, but the strength of FAI depends on other parameter, viz. electric field and neutral winds.

The maximum values of $\mathrm{f}_{t} \mathrm{E}_{s}$ and $\mathrm{f}_{b} \mathrm{E}_{s}$ observed here are $11.2 \mathrm{MHz}$ and $8.3 \mathrm{MHz}$ during the day and $9 \mathrm{MHz}$ and
5.3 MHz during the night. While these represent the maximum values, the most commonly occurring values of $\mathrm{f}_{t} \mathrm{E}_{s}$ and $\mathrm{f}_{b} \mathrm{E}_{s}$ are about $7 \mathrm{MHz}$ and $5 \mathrm{MHz}$ for daytime and $5 \mathrm{MHz}$ and $3 \mathrm{MHz}$ for nighttime. For mid-latitude, $\mathrm{f}_{t} \mathrm{E}_{s}$ are found to be as high as $12 \mathrm{MHz}$ and $11 \mathrm{MHz}$ for daytime and nighttime, respectively (Yamamoto et al., 1992). Pan et al. (1998) have shown the nighttime value to be as high as $13 \mathrm{MHz}$, corresponding to a location close to the equatorial anomaly region. The $\mathrm{f}_{b} \mathrm{E}_{s}$ values for the mid-latitude have been reported to be $7 \mathrm{MHz}$ during daytime and $5.5 \mathrm{MHz}$ during nighttime (Ogawa et al., 2002).

Reddy and Rao (1968) investigated in detail on the interpretation of the $\mathrm{f}_{t} \mathrm{E}_{s}$ (top penetration frequency of $\mathrm{E}_{s}$ ), $\mathrm{f}_{o} \mathrm{E}_{s}$ (the ordinary critical frequency of $\mathrm{E}_{s}$ ) and $\mathrm{f}_{b} \mathrm{E}_{s}$ (blanketing frequency of $\mathrm{E}_{S}$ ) for mid-latitude sporadic $\mathrm{E}$. Using simultaneous observations of electron density measured with rocket-borne instruments and ionograms, they have shown that electron densities deduced from $\mathrm{f}_{b} \mathrm{E}_{s}$ are within an error of $\sim 10 \%$, whereas the same deduced either from $\mathrm{f}_{t} \mathrm{E}_{s}$ or $\mathrm{f}_{o} \mathrm{E}_{s}$ exceed the rocket measured values by $40-100 \%$ during daytime and several hundred percent during nighttime. The electron density can be calculated according to the equation:

$\mathrm{n}=1.24 \times 10^{-8} \mathrm{f}^{2}$

where $\mathrm{f}=\mathrm{f}_{b} \mathrm{E}_{s}$ is in $\mathrm{Hz}$ and $\mathrm{n}$ is in electrons/cc.

Accordingly, the electron densities corresponding to maximum $\mathrm{f}_{b} \mathrm{E}_{s}$ observed here are $8.5 \times 10^{5}$ electrons/cc, and $3.4 \times 10^{5}$ electrons/cc with commonly occurring values of $3.1 \times 10^{5}$ electrons/cc and $1.1 \times 10^{5}$ electrons/cc for daytime and nighttime, respectively. Electron densities have been measured on several occasions both during the day and night over Sriharikota using rocket-borne instruments (e.g. Gupta, $1987 ; 1997)$. The measured electron densities were found to be $7.7 \times 10^{5}$ electrons/cc and $2 \times 10^{4}$ electrons/cc for daytime and nighttime, respectively. It appears that while the electron densities deduced from $\mathrm{f}_{b} \mathrm{E}_{s}$ during daytime are close to the in-situ measured values, the nighttime values are about 5 times larger. Although these two observations are not simultaneous for a detailed comparison, there could be some overestimation in the electron density from the $\mathrm{E}_{s}$ parameters. The overestimation could be partly due to scaling of $\mathrm{f}_{b} \mathrm{E}_{S}$, since it depends on the lowest frequency of the $\mathrm{F}$ layer trace, which could be related to the ionosonde sensitivity. Nighttime electron densities for the mid-latitude during the SEEK campaign have been measured with a peak value of $\sim 1.5 \times 10^{5}$ electrons/cc (Pfaff et al., 1998). Hence, the possibility of electron density during nighttime being of the order of $10^{5}$ electrons/cc is a reality. During nighttime, however, it would require redistribution of plasma in the form of a dense layer since the photoionization process is off.

The role of wind shear is well known for this redistribution process. For the mid-latitudes, since the wind shear mechanism is highly efficient, the occurrence of such a high value of electron density is understandable. For low-latitudes, where the wind shear mechanism is not so efficient as it is at mid-latitudes, it would require a large value of wind shear. 
The observations show that there is a tendency of the radar signal strength to increase with $\mathrm{f}_{t} \mathrm{E}_{s}$ both during the day and night, although the correlation coefficients are less ( $\mathrm{r}=0.35$ for daytime and 0.4 for nighttime). These values are less than that reported for mid-latitude (Hussey et al., 1998). During noontime (11:00-14:00 IST), however, this is not true, although the value of $\mathrm{f}_{t} \mathrm{E}_{s}$ is the highest. The radar signal strength shows a different relationship with $\mathrm{f}_{b} \mathrm{E}_{s}$ during daytime and nighttime: while it seems to decrease with $\mathrm{f}_{b} \mathrm{E}_{s}$ or shows no clear relationship during daytime, it increases during nighttime. Accordingly, the positive relationship of the radar signal strength with $\left(\mathrm{f}_{t} \mathrm{E}_{s}-\mathrm{f}_{b} \mathrm{E}_{s}\right)$ during daytime is clearer than that during nighttime. In fact, during nighttime, the correlation of FAI strength with $\left(\mathrm{f}_{t} \mathrm{E}_{s}-\mathrm{f}_{b} \mathrm{E}_{s}\right)$ is very poor ( 0.18 only). The fact that the radar signal strength is not proportional to $\mathrm{f}_{b} \mathrm{E}_{s}$ during daytime is consistent with the growth rate of the gradient drift instability. During daytime, the recombination rate is more due to large background electron density, which reduces the growth rate of the instability. This relationship also suggests that $\mathrm{f}_{b} \mathrm{E}_{s}$ is the true representative of the electron density.

Yamamoto et al. (1992) found that the irregularities in the nighttime seem to correlate with the activity of the sporadic E layers. But the activity of the sporadic E layers in the post-sunrise period did not correspond to the radar signals. Ogawa et al. (2002) showed that the nighttime FAI became stronger with increasing $\mathrm{f}_{o} \mathrm{E}_{s}-\mathrm{f}_{b} \mathrm{E}_{s}$, suggesting that the FAI generation is closely related to localized density gradients within $\mathrm{E}_{s}$. Further, for the early morning echoes, they have shown that there seems to be no physical relation between $\mathrm{E}_{s}$ and the irregularities responsible for the morning echoes, since the height of $\mathrm{E}_{s}$ and that of the FAI have been found to differ by $10-20 \mathrm{~km}$ in which the $\mathrm{E}_{S}$ is at a higher altitude. However, they have hinted that the morning echoes might be caused by another weak $\mathrm{E}_{s}$ existing below $100 \mathrm{~km}$. Hussey et al. (1998) showed that for the nighttime mid-latitude E region, backscattered power of the FAI is significantly correlated (correlation coefficient, $\mathrm{r}=\sim 0.5$ ) with $\mathrm{f}_{t} \mathrm{E}_{s}$. For the nighttime case presented here, the correlation coefficient is 0.4. Further, the FAI signal strength is poorly correlated $(\mathrm{r}=0.18)$ with $\left(\mathrm{f}_{t} \mathrm{E}_{s}-\mathrm{f}_{b} \mathrm{E}_{s}\right)$, which is in contrast to that reported for mid-latitude by Yamamoto et al. (1992). As far as the daytime correlation is concerned, the correlation between signal strength and $\mathrm{f}_{t} \mathrm{E}_{s}$ is 0.35 and is close to that of nighttime. More importantly, the correlation between the FAI strength and $\left(\mathrm{f}_{t} \mathrm{E}_{s}-\mathrm{f}_{b} \mathrm{E}_{s}\right)$ is $\sim 0.6$. Hussey et al. (1998) showed that the connection between the mid-latitude $\mathrm{E}$ region coherent backscatter and $\mathrm{E}_{S}$ does not necessarily imply a direct cause-and-effect relationship or that the two phenomena are always present simultaneously. They have shown that while sporadic E is needed for coherent scattering to occur, it is not the only condition that has to be satisfied. In fact, the MU radar never detected coherent $\mathrm{E}$ region echoes during summer afternoon hours when ionosonde observed maximum $\mathrm{E}_{s}$ layer activity in both the layer strength and occurrence (Yamamoto et al., 1992). Similar results have also been seen at Chung-Li (Lee et al., 2000).
Reddy (1968) showed that partial reflections from sharp electron density gradients or scattering from small-scale irregularities in $\mathrm{E}_{s}$ can produce partially reflected $\mathrm{E}_{s}$ echoes of sufficient intensity over large frequency ranges above $\mathrm{f}_{b} \mathrm{E}_{s}$. Experimental evidence on this aspect can be found in Ogawa et al. (1998), in which they detected $2-5 \mathrm{MHz}$ signals but not 6 and $7 \mathrm{MHz}$ in their FM-CW sounder observations. This suggests that the signals that were not detected at 6 and $7 \mathrm{MHz}$ are possibly related to weak scattering processes. If we consider that the signals detected by ionosonde at frequencies greater than $\mathrm{f}_{b} \mathrm{E}_{s}$ are due to small-scale irregularities, then the radar observed FAI strength in some sense could be proportional to $\mathrm{f}_{t} \mathrm{E}_{s}$. Since the $\sim 3-\mathrm{m}$ waves are generated through a nonlinear process or mode coupling, it may be hypothesized that the small-scale irregularities may grow when the larger scale irregularities detected by an ionosonde exist. In an event where the ionosonde returns at frequencies higher than $\mathrm{f}_{b} \mathrm{E}_{s}$ are not due to scattering from the irregularities, this expectation would break down. While there could be some relationship, it is not necessary that the irregularities and $\mathrm{E}_{S}$ should coexist, since the growth of the irregularities depends on both the electric field and the electron density gradient. The contrasting features observed in the FAI strength corresponding to the $\mathrm{E}_{S}$ top penetration frequency, especially during noontime and nighttime, clearly suggests this hypothesis, which is consistent with that reported from mid-latitudes (Yamamoto et al., 1992).

For the low-latitude E region and for daytime conditions, Raghavarao et al. (2002) proposed that it is the electrojet current system that affects the low-latitude E region FAI. Their proposal is based on the electrojet model of Anandrao and Raghavarao (1987). They showed that during daytime, an eastward wind increasing with altitude produces whorls of westward currents and downward vertical electric fields that inhibit the development of the gradient drift instability, whereas the eastward wind decreasing with altitude engenders whorls of eastward current and upward electric fields, thereby enhancing the development of the gradient drift instability. While this mechanism appears to be quite sound, the possibility of this, however, needs to be established experimentally. From these observations, it appears that for the low-latitudes, where the electric fields are small, the $\mathrm{E}_{s}$ activities are important for the generation of the FAI as it is at mid-latitudes. The influence of EEJ current system is an additional component and its role needs to be studied further. In addition to these, the role of the neutral winds on the growth of the GDI (Kagan and Kelley, 1998) is also an important aspect to be considered.

\section{Concluding remarks}

We have shown that during the day, the height of FAI is generally below $\mathrm{h}^{\prime} \mathrm{E}_{s}$, while during the night, no such preference is noticed. The nighttime features observed here are quite close to that observed over mid-latitudes. These observations seem to suggest the excitation of gradient drift instability 
on possibly a single layer electron density layer during daytime in contrast to multiple layers during nighttime. The FAI strength is better correlated with $\mathrm{f}_{t} \mathrm{E}_{s}$ and $\mathrm{f}_{b} \mathrm{E}_{s}$ during the night as compared to the day. It is well correlated with $\left(\mathrm{f}_{t} \mathrm{E}_{s}-\mathrm{f}_{b} \mathrm{E}_{s}\right)$ during daytime and very poorly correlated during nighttime. The observed poor correlation of FAI strength with $\left(\mathrm{f}_{t} \mathrm{E}_{s}-\mathrm{f}_{b} \mathrm{E}_{s}\right)$ during the night is remarkable and is in contrast with that observed over mid-latitudes.

Acknowledgements. National MST Radar Facility (NMRF) is operated as an autonomous facility under Department of Space, Government of India. The authors are grateful to NMRF technical staff whose dedicated efforts made possible the observations reported here. The authors are thankful to both the reviewers for their valuable comments for the improvement of the paper.

Topical Editor M. Lester thanks A. Saito and another referee for their help in evaluating this paper.

\section{References}

Anandrao, B. G. and Raghavarao, R.: Structural changes in the currents and fields of the equatorial electrojet due to zonal and meridional winds, J. Geophys. Res., 92, 2514-2526, 1987.

Chau, J. L. and Woodman, R. F.: Low-latitude quasiperiodic echoes observed with the Piura VHF radar in the E region, Geophys. Res. Lett., 26, 2167-2170, 1999.

Chau, J. L., Woodman, R. F., and Flores, L. A.: Statistical characteristics of low-latitude ionospheric field-aligned irregularities obtained with the Piura VHF radar, Ann. Geophys., 20, 12031212, 2002,

SRef-ID: 1432-0576/ag/2002-20-1203.

Choudhary, R. K. and Mahajan, K. K.: Tropical E region field aligned irregularities: Simultaneous observations of continuous and QP echoes, J. Geophys. Res., 104, 2631-2620, 1999.

Fukao, S., Yamamoto, M., Tsunoda, R. T., Hayakawa, H., and Mukai, T.: The SEEK(Sporadic-E-experiment over Kyushu) campaign, Geophys. Res. Lett., 25, 1761-1764, 1998.

Gupta, S. P.: Electron density profiles in the equatorial F-region during evening hours, Adv. Space Res., 7, 69-71, 1987.

Gupta, S. P.: Thin layers of ionization observed by rocket borne probes in equatorial E region, Adv. Space Res., 19, 169-173, 1997.

Hussey, G. C., Schlegel, K., and Haldoupis, C.: Simultaneous 50$\mathrm{MHz}$ coherent backscatter and digital ionosonde observations in the midlatitude E region, J. Geophys. Res., 103, 6991-7001, 1998.

Kagan, L. and Kelley, M. C. : A wind driven gradient drift mechanism for midlatitude E-region ionospheric irregularities, Geophys. Res. Lett., 25, 4141-4144, 1998.

Kelley, M. C.: The earth's Ionosphere: Plasma Physics and Electrodynamics, Academic Press, San Diego, Calif., 1989.

Krishna Murthy, B. V., Ravindran, S., Viswanathan, K. S., Subbarao, K. S. V., Patra, A. K., and Rao, P. B.: Small scale ( $3 \mathrm{~m})$ $\mathrm{E}$ region irregularities at and off the magnetic equator, J. Geophys. Res., 103, 20761-20772, 1998.

Lee, C. C., Liu, J. Y., Pan, C. J., and Igarashi, K.: The heights of sporadic-E layer simultaneously observed by the VHF radar and ionosondes in Chung-Li, Geophys. Res. Lett., 27, 641-644, 2000.
Ogawa, T., Sekito, N., Nozaki, K., and Yamamoto, M.: Height comparison of midlatitude $\mathrm{E}$ region field-aligned irregularities and sporadic E layer, Geophys. Res. Lett., 25, 1813-1816, 1998.

Ogawa, T., Takahashi, O., Otsuka, Y., Nozaki, K., Yamamoto, M., and Kita, K.: Simultaneous MU radar and ionosonde sounder observations of midlatitude $\mathrm{E}$ region irregularities and sporadic E layer, J. Geophys. Res., 107(A10), 1275, doi:10.1029/2001JA900176, 2002.

Pan, C. J., Liu, C. H., Roettger, J., Su, S. Y., and Liu, J. Y.: E region observations over Chung-Li during the SEEK campaign, Geophys. Res. Lett., 25, 1805-1808, 1998.

Pan, C. J., and Rao, P. B.: Low altitude quasi-periodic radar echoes observed by the Gadanki VHF radar, Geophys. Res. Lett., 29, doi:10.1029/2001GL014331, 2002.

Patra, A. K. and Rao, P. B.: High-resolution radar measurements of turbulent structure in the low-latitude E region, J. Geophys. Res., 104, 24 667-24 673, 1999.

Patra, A. K., Sripathi, S., Sivakumar, V., and Rao, P. B.: Evidence of kilometre-scale waves in the lower E region from high resolution VHF radar observations over Gadanki, Geophys. Res. Lett., 29, doi:10.1029/2001GL013340, 2002a.

Patra, A. K., Rao, P. B., Anandan, V. K., Jain, A. R., and Viswanathan, G.: Evidence of intermediate layer characteristics in the Gadanki radar observations of the upper $\mathrm{E}$ region field aligned irregularities, Geophys. Res. Lett., 29, doi:10.1029/2001GL013773, 2002b.

Patra, A. K., Sripathi, S., Sivakumar, V., and Rao. P. B.: Statistical characteristics of VHF radar observations of low-latitude Eregion irregularities over Gadanki, J. Atmos. Solar. Terr. Phys., 66, 1615-1626, 2004.

Pfaff, R., Yamamoto, M., Marionni, P., Mori, H., and Fukao, S.: Electric field measurements above and within a sporadic-E layer, Geophys. Res. Lett., 25, 1769-1772, 1998.

Prakash, S., Subbaraya, B. H., and Gupta, S. P.: Rocket measurements ionisation irregularities in the equatorial ionosphere at Thumba and identifications of plasma irregularities, Indian J. Radio Space Phys., 1, 72-80, 1972.

Raghavarao, R., Patra, A. K., and Sripathi, S.: Equatorial E region irregularities: A review of recent observations, J. Atmos. Solar Terr. Phys., 64, 1435-1443, 2002.

Rao, P. B., Jain, A. R., Kishore, P., Balamuralidhar, P., Damle, S. H., and Viswanathan, G.: Indian MST radar, 1. System description and sample wind measurements in ST mode, Radio Sci., 30, 1125-1138, 1995.

Reddy, C. A. and Rao, M. M.: On the physical significance of the Es parameters $\mathrm{f}_{b} \mathrm{E}_{s}, \mathrm{fE}_{s}$, and $\mathrm{f}_{o} \mathrm{E}_{S}$, J. Geophys. Res., 73, 215-224, 1968.

Reddy, C. A.: Physical significance of the Es parameters $\mathrm{f}_{b} \mathrm{E}_{S}, \mathrm{fE}_{S}$, and $\mathrm{f}_{o} \mathrm{E}_{S}, 2$. Causes of partial reflections from Es, J. Geophys. Res., 73, 5627-5647, 1968.

Sripathi, S., Patra, A. K., Sivakumar, V., and Rao, P. B.: Shear instability as the source of the daytime quasi-periodic radar echoes observed by the Gadanki VHF radar, Geophys. Res. Lett., 30(22), 2149, doi:10.1029/2003GL017544, 2003.

Woodman, R. F., Chau, J. L., Aquino, F., Rodriguez, R. R., and Flores, L. A.: Low- latitude field-aligned irregularities observed in the E-region with the Piura VHF radar: First results, Radio Sci., 34, 983-990, 1999.

Yamamoto, M., Fukao, S., Ogawa, T., Tsuda, T., and Kato, S.: A morphological study on mid-latitude E region field-aligned irregularities observed with the MU radar, J. Atmos. Terr. Phys., 54, 769-777, 1992. 